\title{
Multimodal endoscopic treatment of primary esophago-pleural fistula
}

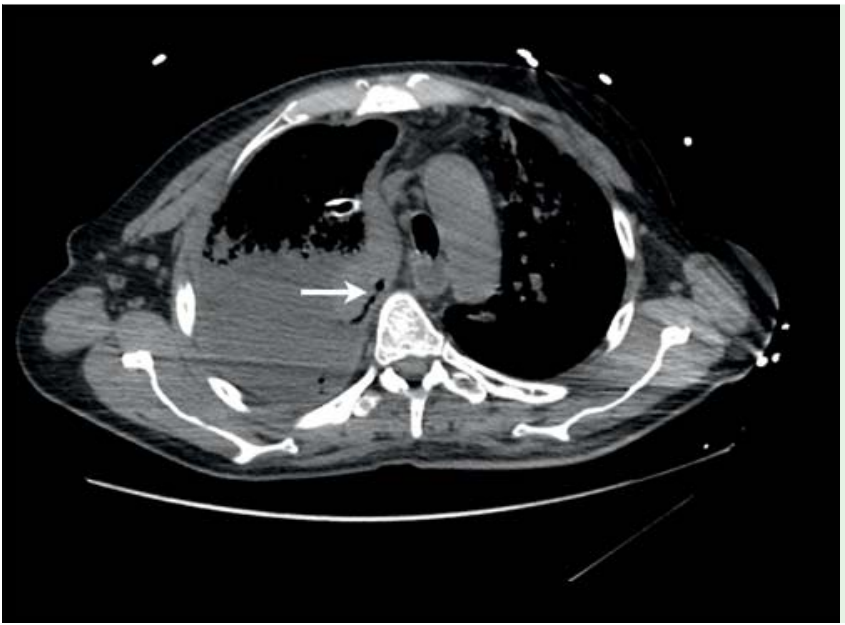

Fig. 1 Computed tomography scan image of massive right pleural corpuscolated effusion. A small esophagopleural fistula could be identified (arrow)

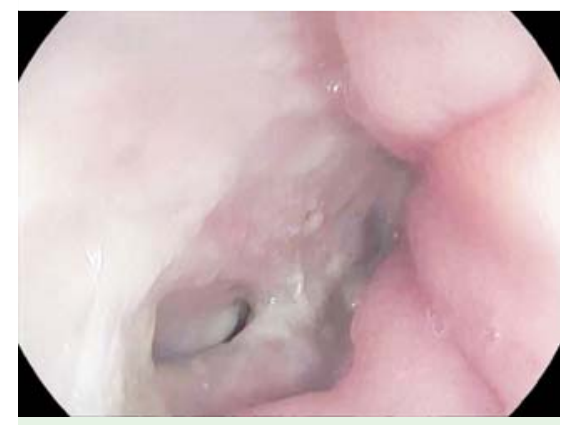

Fig. 2 Endoscopic view of large ulceration of the esophageal wall, with an orifice, about $8 \mathrm{~mm}$ in size, in its distal part.

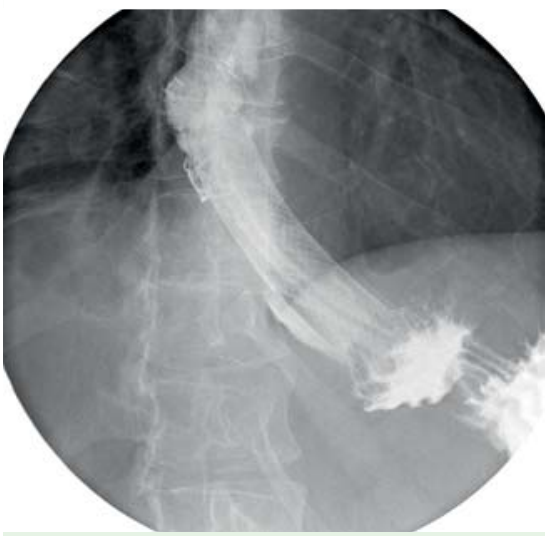

Fig. 3 A radiographic image confirmed that both the over-the-scope clip and the partially covered (colonic) self-expandable metal stent were in place.
A 48-year-old man was admitted to our hospital following the onset of cough, fever, and shortness of breath. Clinical history included psychotic syndrome and recurrent erosive esophagitis.

In the emergency room, a chest radiograph showed right pleural effusion. However, despite full conservative management, his condition worsened rapidly. A computed tomography scan revealed communication between the distal esophageal lumen and the right pleural space ( $\bullet$ Fig. 1). Subsequent upper endoscopy showed extensive ulceration of the esophageal wall, with a small orifice at its distal part ( $\bullet$ Fig. 2).

An over-the-scope clip (OTSC, $12 \mathrm{~mm}$, traumatic type; Ovesco Inc., Tübingen, Germany) was deployed over the orifice ( Video 1). To ensure complete occlusion of the defect, a colonic partially covered metal stent (Niti-S, $22 \mathrm{~mm} \times 10 \mathrm{~cm}$; Taewoong Medical, Inc., Gyeonggi-do, South Korea) was positioned, protecting the orifice against gastroesophageal reflux (॰ Fig. 3).

The patient improved during the subsequent 30 days, and 2 months later, the metal stent was removed using a "stentin stent" technique. Subsequent upper endoscopy showed complete healing of the esophageal wall even though the OTSC was no longer in place.
Primary benign esophago-pleural fistula is a rare but challenging condition, burdened by a high mortality and often requiring surgical treatment [1]. Self-expandable metal stents are well known therapeutic techniques used in the management of leaks and fistulas involving the esophageal wall or anastomosis [2]. Furthermore, the OTSC represents a new endoscopic approach for the closure of upper gastrointestinal leaks and fistulas [3]. However, as in the case described above, a tailored and multimodal approach (stent and OTSC) could be safer and more effective than a single modality, avoiding the need for surgery $[4,5]$.

\section{Endoscopy_UCTN_Code_TTT_1AO_2AC}

Competing interests: None

Helga Bertani, Giuseppe Grande, Vincenzo Giorgio Mirante, Isabella Franco, Santi Mangiafico, Raffaele Manta, Rita Luisa Conigliaro

Gastroenterology and Digestive Endoscopy Unit, NOCSAE Hospital, Modena, Italy

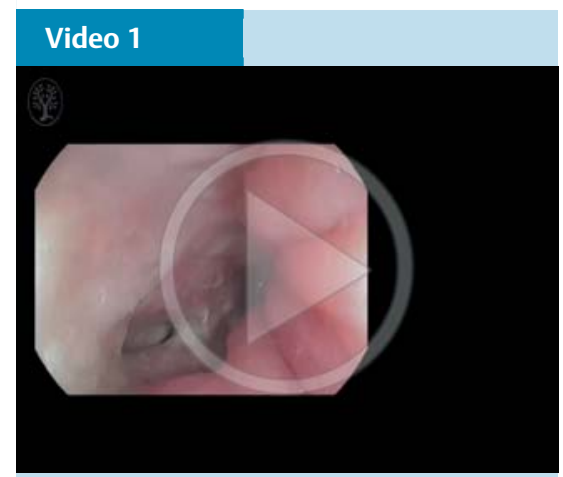

Computed tomography scan and endoscopic view identified an esophago-pleural fistula. Combined treatment with an over-the-scope clip (Ovesco Inc., Tübingen, Germany) and stent placement was performed. Two months later, an upper tract radiograph and an upper endoscopy revealed complete healing of the fistula. 


\section{References}

1 Cherveniakov A, Tzekov C, Grigorov GE et al. Acquired benign esophago-airway fistulas. Eur J Cardiothorac Surg 1996; 10: 713 - 716

2 Van Boeckel PGA, Sijbring A, Vleggaar FP et al. Systematic review: temporary stent placement for benign rupture or anastomotic leak of the oesophagus. Aliment Pharmacol Ther 2011; 33: 1292 - 1301

3 Haito-Chavez Y, Law JK, Kratt T et al. International multicenter experience with an overthe-scope clipping device for endoscopic management of GI defects (with video). Gastrointest Endosc 2014; 80: 610-622

4 González-Haba M, Ferguson MK, Gelrud A. Spontaneous esophageal perforation (Boerhaave syndrome) successfully treated with an over-the-scope clip and fully covered metal stent. Gastrointest Endosc 2016; 83: 650

5 Goenka MK, Goenka U. Endotherapy of leaks and fistula. World J Gastrointest Endosc 2015; 7: $702-713$

\section{Bibliography}

Dol http://dx.doi.org/

10.1055/s-0042-115940

Endoscopy 2016; 48: E298-E299

(c) Georg Thieme Verlag KG

Stuttgart · New York

ISSN 0013-726X

\section{Corresponding author}

Giuseppe Grande, MD

Gastroenterology and Digestive Endoscopy Unit NOCSAE Hospital

via Pietro Giardini 1355

Baggiovara di Modena 41126

Italy

Fax: +39-059-3961216

giuseppegrande1984@gmail.com 